\title{
Assessment of groundwater salinity in Nellore district using multi-electrode resistivity imaging technique
}

\author{
E Chandrasekhar*, Deshmukh Ramesh, Trupti Gurav and T K Biswal \\ Department of Earth Sciences, Indian Institute of Technology Bombay, Powai, Mumbai 400 076, India. \\ *Corresponding author.e-mail: esekhar@iitb.ac.in
}

\begin{abstract}
Multi-electrode resistivity imaging survey with 48 electrodes was carried out to assess the extent of salinity inland, in the shallow subsurface in Nellore district, Andhra Pradesh, in the Eastern Ghats Mobile Belt (EGMB) region. Resistivity data were recorded using Wenner-Schlumberger configuration at nine sites along a profile of about $55 \mathrm{~km}$ in length, laid perpendicular to the coast. An average spacing of $6 \mathrm{~km}$ is maintained between each site. Assessment of groundwater salinity in the study area was made by joint interpretation of the two-dimensional (2D) geoelectrical models of all the sites together with the geochemical analysis results of water samples and geology. At sites closer to the coast, $2 \mathrm{D}$ geoelectrical models of the subsurface indicate low resistivities $(2-50 \Omega \mathrm{m})$ in the depth range from surface up to 15 $\mathrm{m}$. Such low resistivities are due to the high salinity of the groundwater. Geochemical analysis results of water samples at six locations close to the electrical resistivity survey sites also suggest high salinity and high concentrations of total dissolved solids and other chemicals at sites closer to the coast. Away from the coast, the resistivities in the depth range from surface up to $15 \mathrm{~m}$ vary in the range of 50-150 $\Omega \mathrm{m}$. Accordingly, the chemical analysis of water samples collected at these sites also showed relatively low levels of salinity and salt concentrations in them. However, away from the coast, the resistivities vary in the range of 150-1500 $\Omega \mathrm{m}$ in the depth range from 20-40 $\mathrm{m}$. While the aquaculture and agriculture activities may contribute to high salinity at the sites closer to the coast, the presence of deep-seated paleochannels aiding in transporting seawater inland, and water-rock interactions are suspected to be the chief causes for notable salinity at places away from the coast at shallow depths. We opine that the high salinity at shallow depths, coupled with the deep-seated paleochannels transporting seawater, could pose problems to probe further depths particularly using electromagnetic induction methods in the study region.
\end{abstract}

\section{Introduction}

Potable groundwater is one of the important and essential natural resources for survival of human beings. However, the groundwater unfortunately gets contaminated easily through many natural causes, such as landfills, water-rock interaction, and saltwater intrusion, with the latter being the most important factor for groundwater contamination worldwide. Among artificial causes, the agricultural and aquaculture activities are very notable and are the major sources for groundwater contamination. Saltwater intrusion generally arises due to movement of seawater from sea into groundwater aquifers inland. The boundary depicting the freshwater-saltwater zone on the land is usually not fixed and demonstrates a state of dynamical equilibrium moving away from and towards the land, due to seasonal variations in groundwater levels. Accordingly, during pre-monsoon period, the

Keywords. Electrical resistivity imaging; Nellore district; groundwater salinity; geochemistry. 
seawater intrusion is more inland due to low levels of freshwater or absence of rainfall and during postmonsoon period, the effect of seawater contamination with the fresh groundwater is less due to the abundance of rainwater or high levels of freshwater. However, exceptions are at places, where aquaculture activities and water-rock interaction always continue, independent of the seasons and contribute to the increased groundwater salinity.

The issue of saltwater-freshwater intrusion has been a long standing problem and was addressed by many researchers earlier by various methods. Employing electrical resistivity method, Frohlich et al. (1994) studied the groundwater pollution in coastal environment. Combining electrical resistivity data and chemical analysis data of water samples, Ebraheem et al. (1997) assessed the saline water intrusion in northern part of Egypt. Later, combining electrical resistivity and shallow seismic reflection studies, Choudhury et al. (2001) studied the saltwater intrusion in coastal alluvium terrain in northern India. Using the traditional vertical electrical sounding (VES) curves of electrical resistivity, Frohlich and Urish (2002) studied the groundwater quality and its contamination by industrial pollution. Using electrical resistivity, Batayneh (2006) identified three different water bearing formations responsible for the groundwater contamination in the eastern Dead Sea coastal aquifers. Adepelumi (2008) and Adepelumi et al. (2009) highlighted the role of DC resistivity method in effectively distinguishing the saltwater-freshwater interfaces, while demarcating suitable areas for groundwater development in Nigeria. More recently, solely based on geochemical analysis of water samples, Mohan Babu et al. (2012) made a quantitative study of the freshwater contamination in eastern coast of India.

In the present study, we assess the extent of subsurface salinity inlands, in Nellore district of Andhra Pradesh, India, by jointly interpreting the 2D geoelectrical resistivity imaging data and geochemical analysis of water samples and geology in the study region. We also discuss the effects of subsurface salinity and its implications on the difficulties encountered in deciphering the deeper electrical conductivity distribution in the study area.

\section{Geology and groundwater scenario in the study area}

The oldest rock formations in Nellore district are schists and gneisses of Pre-Cambrian age. Various lithounits in the study area, viz., Dagadarthi, AS Peta and Sangam mandal zones occupy Archean rocks, some of whom are represented by granitic gneiss and schists. Hydrogeologically, the rock types occurring in Nellore district are classified as consolidated, semi-consolidated, and unconsolidated formations. Consolidated formations are: granite gneiss, migmatite quartzites, hornblende schist, and granitic gneiss of Archaean Age. The Baironkonda Quartzites/Shales of Cuddapah group are also included in this category. They developed secondary porosity through fracturing and weathering over the ages and thus became water bearing (Central Ground Water Board 2007). Semi-consolidated formations occur in discrete patches. They are: Upper Gondwana sandstones, shales, Cuddalore sandstones and laterites. Among these, the Gondwana sandstones and shales do not form potential aquifers, while the generally laterized Cuddalore sandstones form poor aquifers. Finally, the unconsolidated formations are: alluvium comprising sand, silt, and clay. They are widely seen between Sangam and Nellore. In the inland alluvium, the freshwater aquifers are within the depth of about $15 \mathrm{~m}$ and are mostly developed by borewells. The coastal alluvium of marine origin is dark coloured with fine sand/silt and is mostly saline.

Although the groundwater generally occurs in almost all geological formations, its abundance and yield essentially depends on the recharge conditions and the groundwater condition in the subsurface during, pre- and post-monsoon periods. During pre-monsoon, the depth of water level in alluvial areas varies between 2 and $4 \mathrm{~m}$, while in consolidated formations, it is in the range of $4-15 \mathrm{~m}$. During the post-monsoon period, the average depth of water level in the entire Nellore district is in the range of $2-15 \mathrm{~m}$. More information about detailed geology, mandal-wise groundwater levels, groundwater quality, etc., can be found in the report of Central Ground Water Board (2007).

\section{The database}

\subsection{Electrical resistivity data}

Multi-electrode resistivity imaging survey was carried out with 48 electrodes using WennerSchlumberger (WS) configuration at nine different sites using Syscal-Junior-Switch recording unit of IRIS Instruments, along a profile of length of about $55 \mathrm{~km}$, laid perpendicular to the coast. Figure 1 shows the geographical location of the electrical resistivity survey area, superposed on the map depicting the lakes and rivers around Nellore region. At each site, depending on the availability and accessibility of space, the electrode separations were chosen to be 3 , 4, or $5 \mathrm{~m}$. Accordingly, the total electrode-spread length at each site varies 


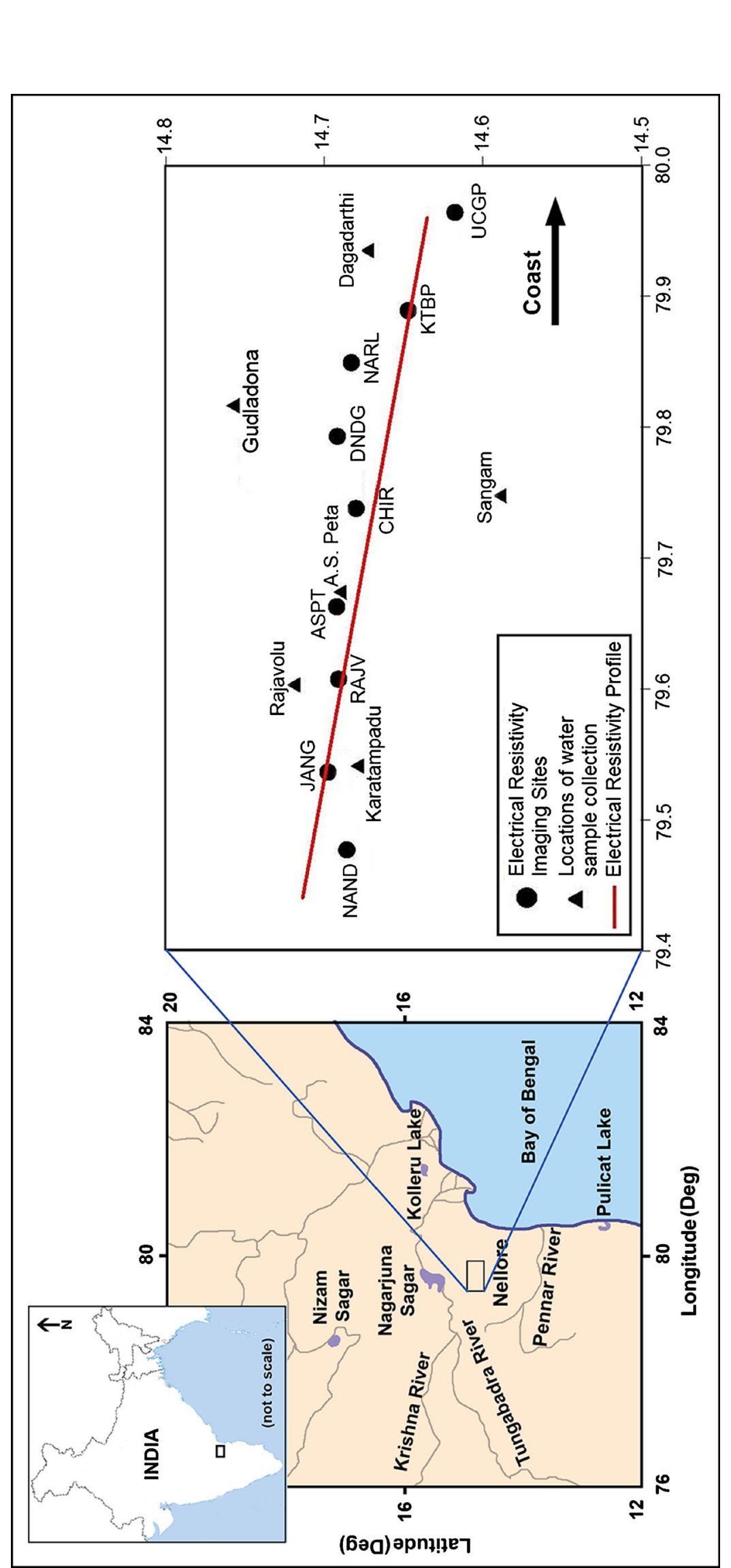

递:

:

$\log ^{0}$

$\sum_{0=1}^{n}$

厌

पै

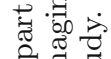

$\omega . \exists$

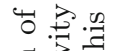

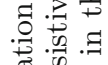

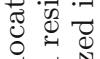

g.

so ․ㅠ

.

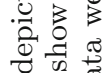

요

宅

낭

行

o

क $\frac{1}{3} \frac{1}{3}$

क्ष

足

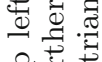

家

象总

品.

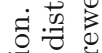

象

웡

艺告

运专

可颉

它要

영

焉

สี ํㅕㅇ

o w

형

을

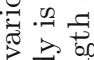

$\infty 0$ 하

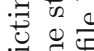

궁

षo

究类

-

\% 


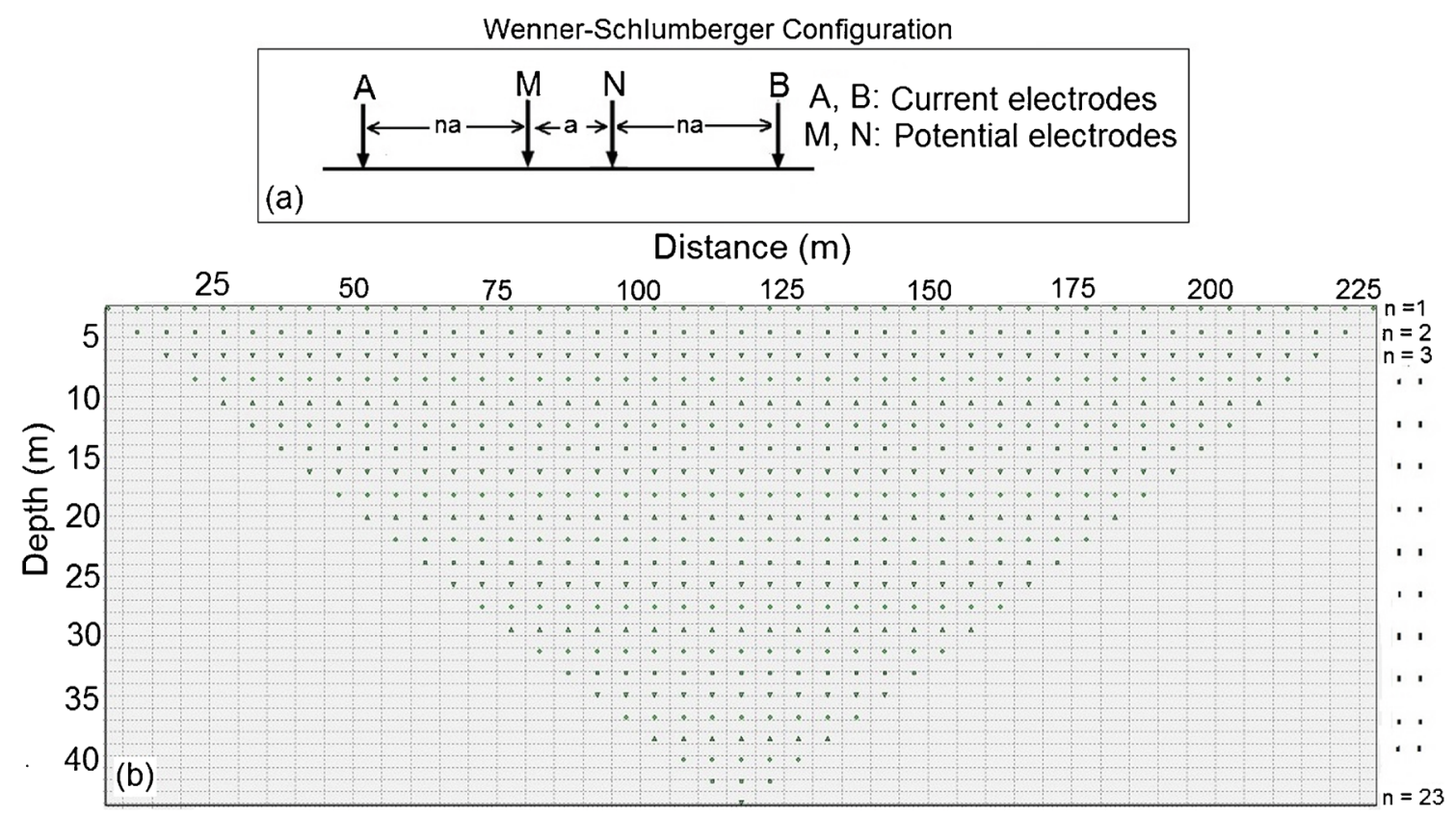

Figure 2. (a) A schematic of the arrangement of two current and two potential electrodes in Wenner-Schlumberger configuration and (b) a schematic of data acquisition geometry of Wenner-Schlumberger configuration, depicting the location of each measured data.

between 144 and $240 \mathrm{~m}$. Figure 2(a) shows the schematic layout of four electrodes in WS configuration. In multi-electrode resistivity imaging surveys, first, all the 48 electrodes are linearly pinned to the ground with fixed electrode spacing between them. A multi-core cable is used to connect all the electrodes and the recording unit. The data acquisition software facilitates one to choose the choice of array configuration a priori. Figure 2(b) shows a schematic drawing of data acquisition geometry of WS configuration, depicting the location of each measured data. Based on the chosen electrode spacing at each site, the total number of data points in WS configuration were set to vary in the range from 500-600, depending on the required higher resolution in the measured apparent resistivity at shallow depths. An average spacing of $6 \mathrm{~km}$ is maintained between each site. The WS configuration has delineated the subsurface electrical resistivity structure up to about 30-40 m. The advantage of WS configuration is that it provides a very good resolution of vertical and horizontal changes in subsurface resistivity (Loke 2004).

\subsection{Water samples from borewells}

A total of six borehole locations, viz., Dagadarthi, Gudladona, Sangam, AS Peta, Rajavolu and Karatamapadu, close to the electrical resistivity survey sites (see figure 1) were identified to ascertain the hydrogeochemical characteristics of the study area. Geochemical analysis data of the water samples at the above six sites were obtained corresponding to pre- and post-monsoon periods from Andhra Pradesh Groundwater Board. The geochemical parameters considered for salinity estimation and classification of water types are: total dissolved solids (TDS), PH values, specific conductance (SC), calcium (Ca), magnesium ( $\mathrm{Mg}$ ), sodium $(\mathrm{Na})$, potassium $(\mathrm{K})$, carbonate $\left(\mathrm{CO}_{3}\right)$, bicarbonate $\left(\mathrm{HCO}_{3}\right)$, chloride $(\mathrm{Cl})$ and sulphate $\left(\mathrm{SO}_{4}\right)$.

\section{Two-dimensional inversion of geoelectrical resistivity imaging data}

Two-dimensional (2D) inversion of measured data was carried out using the RES2DINV software developed by Loke (2001). Noisy datum points were removed from the measured apparent resistivity data prior to $2 \mathrm{D}$ inversion. The RES2DINV code is developed based on the nonlinear smoothness-constrained least-squares (NLSCLS) algorithm of deGroot-Hedlin and Constable (1990) and Sasaki (1992) using finite-difference method. The NLSCLS method essentially solves the equation

$$
\left(J^{T} J+b F\right) d=J^{T} g-b F r
$$

where

$$
F=f_{x} f_{x}^{T}+f_{z} f_{z}^{T}
$$


$f_{x}$ and $f_{z}$ designate the horizontal and vertical flatness filter respectively; $J$ is the Jacobian matrix of partial derivatives; $b$ is the damping factor; $d$ represents model perturbation vector, $g$ is the discrepancy vector and $r$ is a vector containing the logarithm of model resistivity values. In $2 \mathrm{D}$ inversion, the vertical to horizontal flatness filter ratio $\left(f_{z} / f_{x}\right)$ is an important parameter to fine-tune the smoothness-constrain to emphasize vertical or horizontal structures in the inversion model. This value can be defined in the inversion process by setting the relative weights given to the horizontal and vertical flatness filters. For example, for a structure having a predominantly vertical (horizontal) orientation, such as a dyke (sills), the vertical (horizontal) flatness filter is given a greater weight than the horizontal (vertical) filter. More details of NLSCLS method can be found in Loke $(2001,2004)$.

The least-squares optimization algorithm of RES2DINV program attempts to minimize the mean-squared errors between the model response and the observed data iteratively, and produces a model with a smooth variation in the resistivity values as a function of depth (Loke 2001, 2004). The inversion domain of the subsurface having a dimension of $240 \mathrm{~m} \times 35 \mathrm{~m}$ was first discretized into discrete cells of different sizes, with the mesh sizes being finer at the shallow depths and gradually becoming coarser with increase in depth. Since the resolution of the resistivity method decreases exponentially with depth, the inversion optimizes the fit between the data and the model by controlling the damping parameter, $b$. Generally, $b$ should be varied proportional to the noise in the data with its default value being 0.15 . The inversion algorithm reduces $b$ after each iteration. However, a minimum limit for this must be set to stabilize the inversion process. The inversion algorithm also offers a provision to automatically vary the value of $b$ as a function of depth depending on the variations in layer thickness and resistivity.

The RES2DINV program enables to use either the finite-difference or finite-element method to calculate the resistivity values. By default, the program will use the finite-difference method if the dataset does not contain topography. If the dataset contains topography, the default choice is the finite-element method. In the present study, since the study region was devoid of any major undulations and mostly flat, topography was not included in the inversion process. Accordingly, finite-difference method was used to calculate the resistivity values.

Figure 3(a-i) shows the finally inverted geoelectric models of all the electrical resistivity imaging sites shown in figure 1. The sites UCGP (figure 3a), KTBP (figure 3b), and NARL (figure 3c) lie closer to the coast and show almost the entire subsurface up to $30-35 \mathrm{~m}$ as highly conductive. The sites, DNDG (figure 3d), CHIR (figure 3e), ASPT (figure 3f), RAJV (figure 3g), JANG (figure 3h), and NAND (figure 3i) are far away from the coast and are relatively less conductive than those seen in figure $3(\mathrm{a}-\mathrm{c})$ up to $15 \mathrm{~m}$ depth and show a relatively high resistive lithology below $15 \mathrm{~m}$ depth (except at JANG, figure $3 \mathrm{~h}$ ). The resistivity variations at all the sites, only within the top 15-20 $\mathrm{m}$ are of importance, as this depth range indicates the depth of water-levels in these regions. As mentioned earlier, the electrode separations were varied depending on the availability and accessibility of space at each site. Accordingly, the smaller electrode separations give shorter lateral coverage in subsurface imaging at those sites (see figure $3 \mathrm{~b}$, $\mathrm{c}, \mathrm{h}$, and i) and vice-versa (see figure $3 \mathrm{a}, \mathrm{d}, \mathrm{e}, \mathrm{f}$, and $\mathrm{g}$ ). The RMS errors varying between $0.95 \%$ and $2.23 \%$ for all the $2 \mathrm{D}$ resistivity models are well within the acceptable range and are shown in respective plates in the figure. It is pertinent to note here that the low RMS errors indicating the best-fit between the observed and calculated apparent resistivity values at all sites was obtained within 15-20 iterations, indicating the high quality of data recorded at all the sites. The electrical nature of the subsurface and the reasons for variable low resistivities at shallow depths could be further confirmed only by studying the geochemical analysis results of the water samples at places close to and away from the coast.

\section{Geochemical analysis of water samples}

Using the specific conductance values, the salinity $(S)$ of the groundwater samples were calculated using the following formula (Schemel 2001).

$$
S=\sum_{n=1}^{6} K_{n} R^{\left(\frac{n-1}{2}\right)}
$$

where $K_{1}=0.012, K_{2}=-0.2174, K_{3}=25.3283$, $K_{4}=13.7714, K_{5}=-6.4788$ and $K_{6}=2.5842$. $R$ designates the ratio of specific conductance at $25^{\circ} \mathrm{C}$ to that of standard seawater at $25^{\circ} \mathrm{C}(53.087$ milli-siemens per centimeter). Salinity is a dimensionless quantity and is generally expressed in units of parts per thousand. Tables 1 and 2 show the geochemical analysis results of the water samples corresponding to pre-monsoon and post-monsoon periods, respectively.

\section{Results and discussion}

To have a comprehensive understanding of the groundwater scenario and to assess the extent 


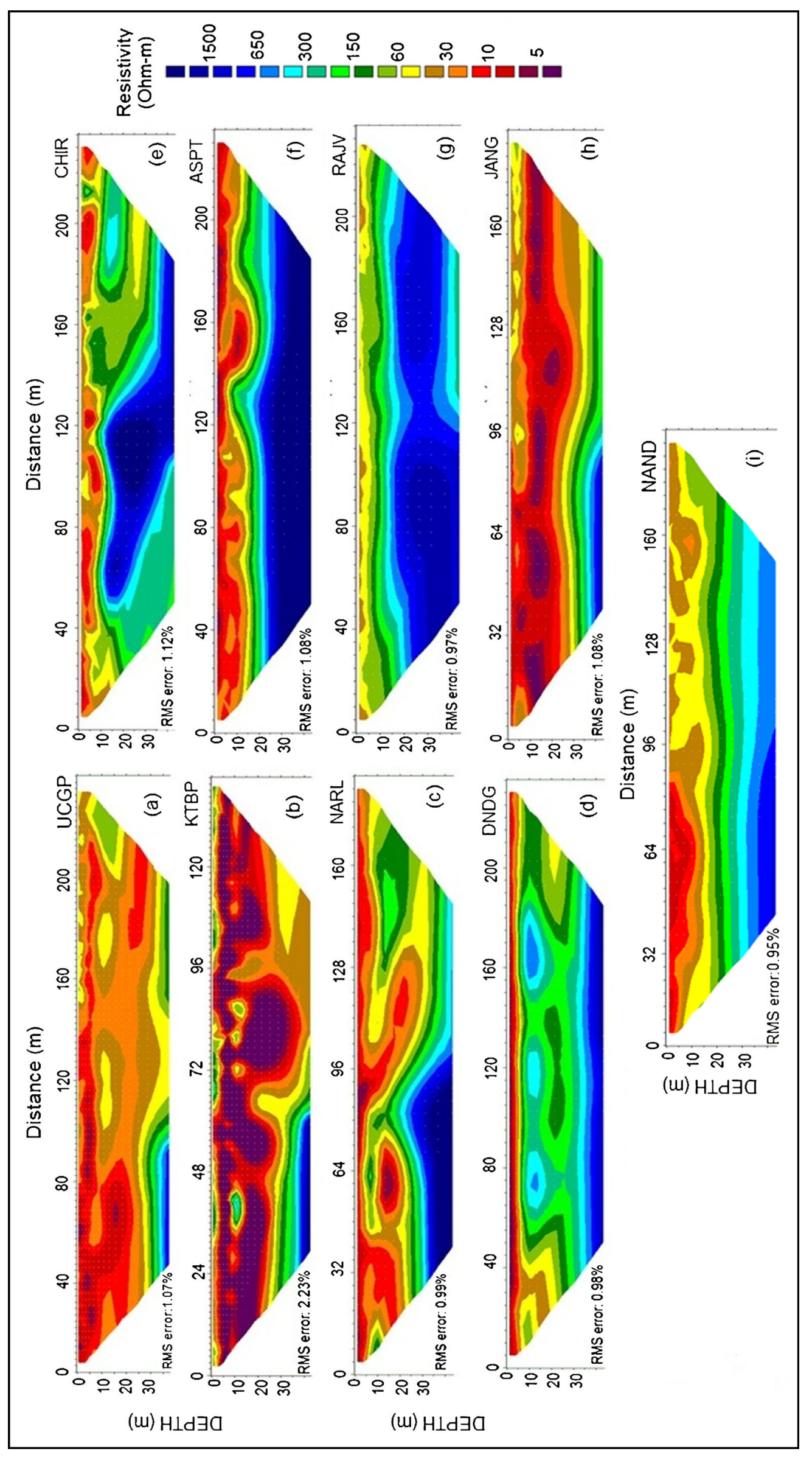

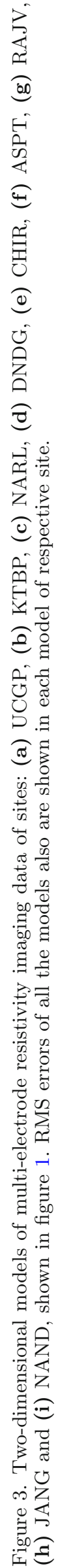


Table 1. Salinity, specific conductance and other salt concentrations of water samples collected at some selected sites (shown as solid triangles in figure 1) during pre-monsoon period.

\begin{tabular}{llcccccc}
\hline Sl. no. & $\begin{array}{c}\text { Name of location } \\
\text { of water sample } \\
\text { collected site }\end{array}$ & $\begin{array}{c}\text { Specific } \\
\text { conductance } \\
(\mu \mathrm{S})\end{array}$ & $\begin{array}{c}\mathrm{TDS} \\
(\mathrm{mg} / \mathrm{l})\end{array}$ & $\begin{array}{c}\text { Salinity } \\
(\mathrm{ppt})\end{array}$ & $\begin{array}{c}\mathrm{Ca} / \mathrm{Mg} \\
(\mathrm{meq} / \mathrm{l})\end{array}$ & $\begin{array}{c}\mathrm{Cl} / \mathrm{HCO}_{3} \\
(\mathrm{meq} / \mathrm{l})\end{array}$ & $\begin{array}{c}\mathrm{TA} / \mathrm{TH} \\
(\mathrm{ppm})\end{array}$ \\
\hline 1 & Dagadarthi & 3317 & 2222 & 1.7325 & 0.54 & 2.22 & 0.43 \\
2 & Gudladona & 3680 & 2466 & 1.9340 & 0.14 & 1.51 & 0.84 \\
3 & Sangam & 2291 & 1535 & 1.1723 & 0.28 & 3.37 & 0.57 \\
4 & AS Peta & 1450 & 972 & 0.7255 & 0.18 & 1.40 & 0.63 \\
5 & Rajavolu & 545 & 365 & 0.2637 & 0.97 & 0.50 & 1.22 \\
6 & Karatampadu & 1185 & 794 & 0.5878 & 0.67 & 3.31 & 0.28 \\
\hline
\end{tabular}

Table 2. Same as table 1, but for post-monsoon period.

\begin{tabular}{llcccccc}
\hline Sl. no. & $\begin{array}{c}\text { Name of location } \\
\text { of water sample } \\
\text { collected site }\end{array}$ & $\begin{array}{c}\text { Specific } \\
\text { conductance } \\
(\mu \mathrm{S})\end{array}$ & $\begin{array}{c}\mathrm{TDS} \\
(\mathrm{mg} / \mathrm{l})\end{array}$ & $\begin{array}{c}\text { Salinity } \\
(\mathrm{ppt})\end{array}$ & $\begin{array}{c}\mathrm{Ca} / \mathrm{Mg} \\
(\mathrm{meq} / \mathrm{l})\end{array}$ & $\begin{array}{c}\mathrm{Cl} / \mathrm{HCO}_{3} \\
(\mathrm{meq} / \mathrm{l})\end{array}$ & $\begin{array}{c}\mathrm{TA} / \mathrm{TH} \\
(\mathrm{ppm})\end{array}$ \\
\hline 1 & Dagadarthi & 3277 & 2196 & 1.7104 & 0.36 & 2.34 & 0.36 \\
2 & Gudladona & 1121 & 751 & 0.5548 & 0.67 & 3.18 & 0.27 \\
3 & Sangam & 1204 & 807 & 0.5976 & 0.59 & 1.43 & 0.36 \\
4 & AS Peta & 2705 & 1812 & 1.3966 & 0.25 & 0.53 & 1.66 \\
5 & Rajavolu & 973 & 652 & 0.4789 & 0.66 & 0.53 & 0.79 \\
6 & Karatampadu & 1258 & 843 & 0.6256 & 0.67 & 3.75 & 0.23 \\
\hline
\end{tabular}

of saltwater influence in the groundwater in the agricultural lands of Nellore district of Andhra Pradesh, the inversion results of 2D electrical resistivity imaging data and the geochemical analysis results of water samples collected at sites close to resistivity survey sites were jointly interpreted. The groundwater levels in the study region during both, pre- and post-monsoon periods, range within the depth interval of about $2-15 \mathrm{~m}$. In this depth range, the geoelectrical models at all sites (figure 3 ) show the subsurface to be highly conductive (2$150 \Omega \mathrm{m})$. Although there are slight variations in the resistivity values at such shallow depths with resistivity marginally increasing with distance from the coast (except at site JANG; figure $3 \mathrm{~h}$ ), the estimated models do not show an appreciable resolution between them to validate this observation more clearly. In other words, the subsurface resistivities within the depth range from surface up to $15 \mathrm{~m}$ beneath all the stations more or less match with one another and do not offer any significant information to distinguish the sites on the lines of saline water influence zones. Therefore, using the geochemical analysis results of water samples corresponding to pre- and post-monsoon periods, their salinities were estimated (tables 1 and 2) using equation (1).

Near the coastal areas in Nellore district, the groundwater is generally pumped excessively and mixed with seawater to reach the desired salinity levels of brackish water, for its subsequent use in aquaculture activities. This generally causes the groundwater levels to drop significantly thereby leading to depletion of aquifers, and contributing to salinization of adjacent environments (Rönnbäck et al. 2003; Rajitha et al. 2007). The high conductivity of the subsurface from surface up to 30 $35 \mathrm{~m}$ depth seen at the sites UCGP, KTBP and NARL (figure $3 \mathrm{a}-\mathrm{c}$ ) undoubtedly supports such an observation and stands as testimony to such activities.

As well known, the degree of salinity in groundwater is generally measured by estimating the ionic concentrations of $\mathrm{Ca}: \mathrm{Mg}, \mathrm{Cl}: \mathrm{HCO}_{3}$ (in milliequivalents/litre (meq/l)) and the ratio of total alkalinity to total hardness, TA:TH (in ppm) of water samples. If the values of $\mathrm{Ca}: \mathrm{Mg}$ and $\mathrm{TA}: \mathrm{TH}$ ratios are less than unity and $\mathrm{Cl}: \mathrm{HCO}_{3}$ ratio is greater than unity, then the groundwater in that region is said to have been contaminated with seawater (Rao et al. 2005). The salinity values of the water samples collected at Dagadarthi, Gudladona, and Sangam are very high during both, pre- and postmonsoon (tables 1 and 2). Since these places are close to the electrical resistivity imaging sites, UCGP, KTBP, and NARL, it can be further confirmed that the high conductivity seen beneath these three stations is due to the presence of high salinity in the groundwater. Because of the proximity of these sites to the coast, the high salinity seen during post-monsoon period is essentially due to excessive aquaculture activities that have contributed to the increased groundwater salinity. 
Figure 3(d-g) shows the alluvium top layer up to $15 \mathrm{~m}$ depth to be low resistive, underlain by high resistive zone, representing the granites and gneissic schist host rocks. Comparatively, the salinities of the groundwater within the alluvium at these places are slightly lower than those at sites close to the coast (figure $3 \mathrm{a}-\mathrm{c}$ ). However, at the site ASPT (figure 3f), the salinity is abnormally high during post-monsoon with low $\mathrm{Ca}: \mathrm{Mg}$ ratio (table 2). The subsurface resistivity structure within the $15 \mathrm{~m}$ depth is also low resistive, underlain by a high-resistive lithology. Interestingly, the $\mathrm{Cl}: \mathrm{HCO}_{3}$ ratio is $<1$ at this site (table 2 ). The less than unity values of $\mathrm{Cl}: \mathrm{HCO}_{3}$ ratio is probably due to low chloride content in the water, suggesting the absence of seawater intrusion in this region during the post-monsoon period. Due to the presence of high resistive zone below $15 \mathrm{~m}$ depth at ASPT, the possibility of saline water intrusion into the upper layers is less likely. Thus, at this site, the high salinity could be due to water-rock interaction between water and magnesium rich dolomitic limestones, leading to high magnesium in groundwater. However, the possibility of dissolved fertilizers in the groundwater cannot be ruled out either (because TDS $>1000 \mathrm{mg} / \mathrm{l}$ ) as a cause for high salinity.

Figure $3(\mathrm{~g})$ shows a slightly higher resistivity (50-150 $\Omega \mathrm{m}$ ) of the top layer (up to $15 \mathrm{~m}$ depth) at RAJV, compared to the resistivity at other sites in that depth range. The chemical analysis results of water sample close to this site also show low TDS, Cl: $\mathrm{HCO}_{3}$, and TA:TH values (tables 1 and 2 ), indicating no influence of saline water. The relatively higher $\mathrm{Ca}: \mathrm{Mg}$ value at this site could be due to the presence of $\mathrm{Mg}$ rich dolomite. On the whole, the groundwater scenario at RAJV suggests the presence of uncontaminated groundwater at this site, as there is quite a good agreement between the salinity concentrations, geochemical analysis results (tables 1 and 2), and the subsurface resistivity structure (figure $3 \mathrm{~g}$ ).

Unlike at most other sites, the alluvium thickness at JANG (figure $3 \mathrm{~h}$ ) is more and the entire section from surface up to $30-35 \mathrm{~m}$ depth shows high conductive alluvial sediments. The presence of high-resistive lithology is seen only beyond 35 $\mathrm{m}$ depth. The chemical analysis results of water samples corresponding to the well site, Karatampadu (tables 1 and 2), which is close to JANG (see figure 1) also suggest high salinity of groundwater in this zone. This indicates the presence of probable seawater intrusion at sites as far as $65 \mathrm{~km}$ away from the coast, even though the salinity at this site is lower than that at sites close to the coast. The question to be asked here is how can a place situated as far as $65 \mathrm{~km}$ inland from the coast contain such high salinity in the groundwater? The answer lies in the subsurface resistivity structure at JANG (see figure 3h). Babu (2001) explains the presence of superposed drainage patterns and paleochannels north of Pennar River, as illustrated by changes in the river course (see also Reddy and Chandrakala 2004). This suggests that the seawater in its journey from the coast to inland, through these deep seated paleochannels could have travelled well inland, into the study region. At JANG, since the entire subsurface up to $35 \mathrm{~m}$ is only sediments, the saline water could have easily percolated into the media and up to the surface. However, at most other sites, the highly resistive lithologies (figure $3 \mathrm{c}-\mathrm{g}$ ), could have prevented such upward movement of saline water at those sites.

The above discussion clearly suggests that in the study region, it is difficult to identify a probable boundary separating the saline and nonsaline regions. Because, the entire region appears to be saline (except RAJV (figure 3g)), although the relative salinity levels differ drastically from the sites close to coast to those well inland. It appears that the presence of high-resistive lithology beneath most of the sites has played a vital role in preventing the upward movement of seawater to shallow levels, as was confirmed at JANG (figure 3h), where the high-resistive lithology is absent.

The multi-electrical resistivity imaging survey proves to be very effective and aptly serves the right purpose in properly understanding the nature of the subsurface in and around coastal regions and their salinity. The depth of investigation of resistivity up to $35 \mathrm{~m}$ also appears to be sufficient to understand the groundwater conditions in such regions. The relatively high conductive nature of the subsurface due to high salinity in shallow subsurface, coupled with the deep-seated paleochannels transporting seawater, could act as a deterrent to probe further depths in the study region, particularly using electromagnetic induction methods.

\section{Conclusions}

This study presents the joint interpretation of the results of multi-electrode electrical resistivity imaging surveys and geochemical analysis of water samples in the study region of Nellore district to assess the groundwater salinity. The derived 2D geoelectrical models clearly depict the lateral extent and depth of salinity in the groundwater in the study region. Except the site, RAJV, the entire region within the depth range from surface up to about $20 \mathrm{~m}$ is highly conductive, suggesting the influence of seawater intrusion, waterrock interaction, and the acute aquaculture and agricultural activities, which invariably make the groundwater highly saline. These observations are confirmed by the geochemical analysis results of 
water samples in the study area (figure 1). It is interesting to observe that the study region appears to be saline although the relative salinity levels differ marginally from the sites close to the coast to those well inland. The presence of superposed drainage patterns and paleochannels north of Pennar River, carrying seawater inland are believed to be one of the reasons for high salinity even in areas well inland and far away from the coast. The relatively high conductive nature of the subsurface due to high salinity at shallow depths, coupled with the deep-seated paleochannels transporting seawater, could act as a major deterrent to probe deeper depths using electromagnetic methods. However, deeper resistivity imaging surveys using more electrodes could perhaps improve the present understanding and throw some more light on the nature of subsurface electrical resistivity vis-à-vis the groundwater salinity as a function of depth.

\section{Acknowledgements}

The authors thank the Ministry of Earth Sciences (MoES), Govt. of India, for sponsoring the work through a research project \#MoES/P.O. (Seismo)/ 1(69)/2009 to EC. The authors thank D Chandrasekharam for his help in interpretation of geochemical data. EC and DR thank the villagers at Nellore district for their kind cooperation at all the site locations, where the electrical resistivity imaging surveys were carried out. They also thank the staff of Andhra Pradesh State Groundwater Board for providing the geochemical data used in this study. The handling editor Pawan Devangan, Adepelumi, and an anonymous referee have provided valuable reviews that helped to improve the quality of the paper. The authors thank Mr. D Subhakar for his help in drawing figure 1.

\section{References}

Adepelumi A A 2008 Delineation of saltwater intrusion into the freshwater aquifer of Lekki peninsula, Lagos, Nigeria, Proc. of $3^{\text {rd }}$ International Conference on Water Resources and Arid Environments and the $1^{\text {st }}$ Arab Water Forum, 16-18 November 2008, Saudi Arabia, pp. $1-15$.

Adepelumi A A, Ako B D, Ajayi T R, Afolabi O and Omotoso E J 2009 Delineation of saltwater intrusion into the freshwater aquifer of Lekki peninsula, Lagos, Nigeria; Environ. Geol. 56 927-933, doi: 10.1007/s00254008-1194-3.

Babu M M, Viswanadh G K and Rao S V 2012 Assessment of saltwater intrusion along coastal areas of Nellore District, AP; Int. J. Scientific Eng. Res. 4 173-178.

Babu V R R M 2001 Plate tectonic history of the Indian plate, Nellore-Khammam Schist Belt; Indian Acad. Geosci. Publ., pp. 1-183.

Batayneh A T 2006 Use of electrical resistivity methods for detecting subsurface fresh and saline water and delineating their interfacial configuration: A case study of the eastern Dead Sea coastal aquifers, Jordan; Hydrogeol. J. 14 1277-1283.

Central Ground Water Board 2007 Ground water information Nellore District, Andhra Pradesh, Southern Region, Report, pp. 1-37.

Choudhury K, Saha D K and Chakraborty P 2001 Geophysical study for saline water intrusion in a coastal alluvial terrain; J. Appl. Geophys. 46 189-200.

deGroot-Hedlin C and Constable S 1990 Occam's inversion to generate smooth, two-dimensional models from magnetotelluric data; Geophysics 55 1613-1624.

Ebraheem A A M, Senosy M M and Dahab K A 1997 Geoelectrical and hydrogeochemical studies for delineating groundwater contamination due to saltwater intrusion in the northern part of the Nile delta, Egypt; Ground Water 35 216-222.

Frohlich R K and Urish D W 2002 The use of geoelectrics and test wells for the assessment of groundwater quality of a coastal industrial site; J. Appl. Geophys. 50 261278.

Frohlich R K, Urish D W, Fuller J and Reilly M O 1994 Use of geoelectrical method in groundwater pollution surveys in a coastal environment; J. Appl. Geophys. 32 139-154.

Loke M H 2001 Electrical imaging surveys for environmental and engineering studies: A practical guide for $2 \mathrm{D}$ and $3 \mathrm{D}$ surveys, Geotomo Software, Malaysia, pp. 1-67.

Loke M H 2004 Tutorial: 2-D and 3-D electrical imaging surveys; GeotomoSoftware, Malaysia, pp. 1-136.

Rajitha K, Mukherjee C K and Vinu Chandran R 2007 Applications of remote sensing and GIS for sustainable management of shrimp culture in India; Aquacultural Engineering 36(1) 1-17.

Rao N S, Nirmala I S and Suryanarayana K 2005 Groundwater quality in a coastal area: A case study from Andhra Pradesh, India; Environ. Geol. 48 543-550.

Reddy P R and Chandrakala K 2004 Seismicity in and around Ongole, Andhra Pradesh - an appraisal; J. Indian Geophys. Union 8 143-146.

Rönnbäck P, Troell M, Zetterström T and Babu D E 2003 Mangrove dependence and socio-economic concerns in shrimp hatcheries of Andhra Pradesh, India; Environ. Conserv. 30(4) 344-352.

Sasaki Y 1992 Resolution of resistivity tomography inferred from numerical simulation; Geophys. Prospect. $40453-$ 464.

Schemel L E 2001 Simplified conversions between specific conductance and salinity units for use with data from monitoring studies; Interagency Ecological Program Newsletter 14(1) 17-18. 